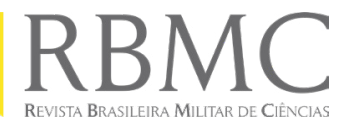

ISSN 2447-9071

doi https://doi.org/10.36414/rbmc. v5i13.16

Contato para correspondência: Rogério José de Almeida

E-mail:

rogeriopucgo@gmail.com

Conflito de interesse: Não

Financiamento: Fundação de Amparo à Pesquisa do Estado de Goiás (FAPEG), Coordenação de Aperfeiçoamento de Pessoal de Nível Superior (CAPES) e Conselho Nacional de Desenvolvimento Científico e Tecnológico (CNPq)

Recebido: 14/10/2019

Aprovado: 11/11/2019

\section{0 dependente químico residente em comunidade terapêutica: da triagem à adaptação a uma nova vida}

\section{The chemical dependent resident in therapeutic community: to the screening for a new life}

Bruna Vicente de Oliveira', Gabriela Fernandes Carnot Damacena', Sonis Henrique

Rezende Batista', Rogério José de Almeida ${ }^{1,2}$

${ }^{1}$ Pontifícia Universidade Católica de Goiás - PUC Goiás

${ }^{2}$ Faculdade da Polícia Militar - FPM

\section{Resumo}

Opresente artigo teve por objetivo compreender os processos e estratégias de triagem, acolhimento e adaptação de indivíduos dependentes de drogas em comunidades terapêuticas. Trata-se de umestudo transversal descritivo com abordagem qualitativa e exploratória com 43 comunidades terapêuticas queatendem dependentes deálcool e outras drogas equeestãolocalizadas no município de Goiânia, região metropolitana ecidade de Anápolis. Foram analisadas variáveis constantes de um questionário semiestruturado. As categorias explicativas que emergiram da análise foram: 1) A triagem antes de entrarna comunidade;2) Aadaptação dentro das comunidades terapêuticas;3) A rotina diária dentro das comunidades terapêuticas. Observou-sequeno processo de triagem as comunidades investigadas priorizam pela vontade do indivíduo em detrimento das internações compulsórias, objetivando o sucesso terapêutico. Quanto ao processo de adaptação, notou-se que, apesar de algumas variações, todas as entidades pesquisadas reconhecem a necessidade de abordar o período de maneira adequada e acolhedora. Finalizado o período estipulado para a adaptação, os residentes começam a vivenciar de maneira mais intensa a rotina diária da comunidade, bem como suas respectivas normas. Aanálise das entrevistas possibilitou compreender os impactos desses três processos iniciais na vida do dependente que está buscando um tratamento para sua doença. O entendimento desse fenômeno, especificamente relacionado às comunidades auxilia em uma melhor qualificação desses processos de recebimento do indivíduo, desde o momento em que ele chega à comunidade até sua completa adaptação a rotina estabelecida pela entidade.

Palavras-Chave: Comunidade terapêutica, Dependência química, Tratamento.

\begin{abstract}
This article aims to understand the process and strategies of selection, reception and adaptation of individuals on drug addiction in therapeutic communities. It was a descriptive cross-sectional exploratory study with a qualitative approach with 43 therapeutic communities that serve dependents. Constantvariables were analyzed in a semi-structured questionnaire. The explanatory categories were: 1) screening before entering the community; 2) The adaptation within the therapeutic communities; 3) The daily routine within the therapeutic communities. It was observed that the therapeutic communities screening process gives priority to the individual's will over compulsory intervention, aiming therapeutic success. As for the adaptation process, it was noted that, despite some variations, all the entities surveyed recognize the need to approach the time at the communities in an appropriate and welcoming way. Finished adaptation period, it was found that residents began to experience more intensely the community's daily routine and rules. Though the data analysis, it was possible to better understand the impacts of this initial approach on the life of the person on misuse of substances looking for treatment. The understanding of this phenomenon, specifically related to the community helps in a better qualification of these individual receiving processes, from the moment he arrives at the community until its complete adaptation routine established by the entity.
\end{abstract}

Keywords: Therapeutic community, Chemical dependency, Treatment. 


\section{Introdução}

O uso abusivo de drogas, sejam lícitas ou ilícitas, é atualmente uma das maiores preocupações existentes na sociedade e entre os governantes e cientistas do mundo inteiro. É um problema crescente que vem acometendo uma parcela significativa da população. No cerne deste problema está a dependência química, ou síndrome de dependência. De acordo com a Classificação Internacional de Doenças (CID-10) é caracterizada por um desejo frequente e forte de consumir substâncias psicoativas, ou seja, qualquer droga que altera o comportamento e causa abstinência em sua ausência, se constituindo hoje em um problema de saúde pública'.

Antes de tudo, é preciso compreender que o dependente químico é um ser humano doente e, como tal, carrega consigo não só uma doença grave, mas também toda carga cultural negativa instituída pela atual sociedade. O próprio dependente químico tende a ter uma visão de mundo bastante negativa de si próprio, por conta de diversos fatores, que vai desde problemas em sua adolescência até traumas mais graves ocorridos em sua curva vital².

É nesse contexto que aparecem as chamadas Comunidades Terapêuticas que visam dar apoio aos dependentes químicos para que estes consigam ter autonomia e capacidade de controle sobre suas vontades ${ }^{3}$. Assim, essas comunidades funcionam como instituições sociais que buscam remediar, restaurar ou curar o dependente químico, procurando mudar a pessoa inteira 4 .

As comunidades terapêuticas visam promover a reabilitação física e psicológica, recuperação, resgate da cidadania e reinserção social do indivíduo dependente por meio de programas terapêuticos que podem envolver laborterapia, convivência comunitária, desenvolvimento de atividades profissionalizantes, programas culturais, atividades religiosas e espirituais, atendimento às famílias, dentre outras ${ }^{5}$. São instituições criadas pela sociedade civil como um meio de educar o indivíduo pela relação com pares e considerando seu contexto social, ajudando-o a se reinserir socialmente sem que isso traga prejuízos tanto ao próprio sujeito quanto aos seus vínculos sociais².

As características dessa abordagem de tratamento refletemse em ambientes residenciais, livres de substâncias tóxicas, que usam como modelo hierárquico etapas de tratamento que inserem o residente em níveis cada vez maiores de responsabilidade social e pessoal. É utilizada a influência dos próprios companheiros para ajudar cada pessoa a aprender e assimilar as normas sociais e desenvolver habilidades cada vez mais eficazes para reintegração social ${ }^{6}$.

No Brasil, as comunidades terapêuticas estão enquadradas na Portaria n. 3088/2011 que prevê a criação, ampliação e articulação de serviços de cuidado a saúde para pessoas com sofrimento ou transtorno mental decorrentes ao uso de drogas. Os dependentes químicos que se internarem nas comunidades podem permanecer por até nove meses. Essas comunidades devem funcionar de forma articulada com a atenção básica e com o Centro de Atenção Psicossocial?.

Para que as comunidades atuem de maneira organizada, padronizada e de acordo com as demandas jurídicas e sanitárias, foi instituída a Resolução RDC n. 29, de 30 de junho de 2011 que dispõe sobre os requisitos de segurança sanitária para o funcionamento de instituições que prestem serviços de atenção às pessoas com transtornos decorrentes do uso, abuso ou dependência de substâncias psicoativas. Esta resolução estabelece circunstâncias básicas de estruturação e manutenção que qualquer comunidade terapêutica deve ter para dar condições sanitárias e de saúde mínimas para os residentes da instituição e também ao corpo administrativo ${ }^{8}$.

Mediante os fatores problematizados identifica-se a importância da compreensão dos processos e regras utilizadas pelas comunidades terapêuticas para a aceitação de novos residentes. Assim, o objetivo do presente estudo é compreender os processos e estratégias de triagem, acolhimento e adaptação de indivíduos dependentes de drogas em comunidades terapêuticas.

\section{Métodos}

Trata-se de um estudo transversal descritivo com abordagem qualitativa com 43 comunidades terapêuticas que atendem dependentes de álcool e outras drogas e que estão localizadas no município de Goiânia e região metropolitana, incluindo também a cidade de Anápolis pela sua importância no estado de Goiás.

Foram pesquisadas Comunidades Terapêuticas localizadas na Região Metropolitana de Goiânia, assim definida pela Lei Complementar Estadual n 27, de 30/12/1999, alterada pela Lei Complementar n 78, de 25/03/2010, compreendida por 20 municípios, sendo estes: Goiânia, Abadia de Goiás, Aparecida de Goiânia, Aragoiânia, Bela Vista de Goiás, Bonfinópolis, Brazabrantes, Caldazinha, Caturaí, Goianápolis, Goianira, Guapó, Hidrolândia, Inhumas, Nerópolis, Nova Veneza, Santo Antônio de Goiás, Senador Canedo, Teresópolis de Goiás e Trindade. Além destes, também foi incluído nesta pesquisa o município de Anápolis, em função de seu porte populacional e proximidade com a capital.

Foram localizadas um total de 83 entidades denominadas de Comunidades Terapêuticas cadastradas junto ao Fórum Goiano de Prevenção e Enfrentamento ao Uso do Crack e Outras Drogas e ao Grupo Executivo de Enfretamento as Drogas - GEED. Este último um órgão estadual. 
Buscou-se, por meio de contato telefônico, identificar se a entidade contatada era realmente um estabelecimento de acolhimento voluntário para dependentes químicos e explicando do que se tratava a pesquisa, em breve relato, comunicando da necessidade de se promover a visita e coleta de informações com a aplicação do questionário. Do contato realizado, gerouse o quadro 1 que demonstra os motivos pelos quais algumas entidades foram excluídas da amostra final:

Quadro 1 - Motivos de exclusão das entidades previamente cadastradas nos órgãos oficiais.

\begin{tabular}{l|c|c|c}
\hline Motivação & Frequência & Percentual & $\begin{array}{c}\text { Percentual } \\
\text { acumulado }\end{array}$ \\
\hline $\begin{array}{l}\text { Sem retorno aos contatos } \\
\text { realizados }\end{array}$ & 2 & 5,0 & 5,0 \\
\hline Recusa em participar & 3 & 7,5 & 12,5 \\
\hline $\begin{array}{l}\text { Clínica Involuntária } \\
\text { Encontrava-se fechada, sem } \\
\text { atividades }\end{array}$ & 13 & 35,0 & 47,5 \\
\hline $\begin{array}{l}\text { Pouco tempo de funciona- } \\
\text { mento (menos de um mês) }\end{array}$ & 2 & 32,5 & 80,0 \\
\hline $\begin{array}{l}\text { Outra atividade desen- } \\
\text { volvida }\end{array}$ & 4 & 5,0 & 85,0 \\
\hline $\begin{array}{l}\text { Questionário recusado. } \\
\text { Respostas não confiáveis }\end{array}$ & 2 & 10,0 & 95,0 \\
\hline \begin{tabular}{l} 
Total \\
\hline
\end{tabular} & 40 & 100,0 & 100,0 \\
\hline
\end{tabular}

Dentre os 21 municípios pesquisados, nove deixaram de ser visitados uma vez que sete não possuíam entidades cadastradas pelos órgãos consultados e duas tinham estabelecimentos previstos na listagem, mas englobaram os motivos descritos no quadro 1 acima. Há que ressaltar que uma comunidade terapêutica que respondeu o questionário estava cadastrada em um município, mas ao checar seus documentos, territorialmente ele pertencia a cidade vizinha, uma vez que a sede se situa numa região limítrofe, permanecendo no estudo por ainda assim ser da Região Metropolitana.

Após a verificação e confirmação in loco do estabelecimento, restaram 43 comunidades terapêuticas, em 12 cidades, que totalizaram a pesquisa e receberam a visita dos pesquisadores.

As Comunidades que assim se identificaram, no momento do telefonema, eram informadas da pesquisa e do interesse em se realizar o trabalho de campo para coleta das informações. Era solicitado que a pessoa que fosse participar da entrevista entendesse de todo o funcionamento da instituição, além de conhecer a história, a parte documental e financeira, o perfil de atendimento e a rotina de atendimento oferecido aos acolhidos. Em geral essa pessoa era a (o) responsável pela comunidade. As visitas às instituições foram realizadas no período compreendido entre os meses de julho de 2014 a maio de 2015.

A análise das entrevistas baseou-se na perspectiva da Teoria Fundamentada nos Dados (Grounded Theory), que visa compreender a realidade a partir da percepção ou significado que certo contexto ou objeto tem para a pessoa, gerando conhecimentos, aumentando a compreensão e proporcionando um guia significativo para a ação. Logo, essa técnica de análise consiste em uma abordagem de pesquisa qualitativa com o objetivo de descobrir teorias, conceitos e hipóteses, baseados nos dados coletados e nas experiências vivenciadas pelos atores sociais, ao invés de utilizar padrões predeterminados ${ }^{9}$.

Após a transcrição das entrevistas, as etapas chamadas de codificação dos discursos foram seguidas10. Na primeira, chamada de codificação aberta, as entrevistas foram lidas de forma rigorosa pelos pesquisadores, selecionando os núcleos de sentido mais relevantes, criando assim categorias de análise.

A segunda etapa consistiu na codificação axial em que foram destacadas as principais categorias explicativas do fenômeno e também criadas as subcategorias. E, na terceira e última etapa, foi realizada a codificação seletiva que consistiu na organização de uma narrativa descritiva sobre o fenômeno central do estudo, selecionando o que realmente importa no desenvolvimento do modelo teórico representativo do fenômeno pesquisado.

Esta pesquisa está inscrita na Comissão Nacional de Ética em Pesquisa - CONEP com a CAAE: 12416213.1.0000.0037 e foi aprovada pelo Comitê de Ética em Pesquisa - CEP da Pontifícia Universidade Católica de Goiás - PUC Goiás.

\section{Resultados}

As categorias explicativas do fenômeno que emergiram da codificação dos discursos das entrevistas foram: 1) A triagem antes de entrar na comunidade; 2) A adaptação dentro das comunidades terapêuticas; 3 ) A rotina diária dentro das comunidades terapêuticas.

\section{A triagem antes de entrar na comunidade}

Observou-se que os procedimentos de triagem realizados pelas comunidades terapêuticas não apresentam um padrão rígido e definido, ou seja, cada uma institui seu processo de admissão, respeitando suas regras internas.

Durante a análise das entrevistas foi possível observar que, apesar dos variados processos de triagem, um grande número de comunidades aborda temas de cunho pessoal, especial- 
mente a demonstração de real interesse no processo de internação e na futura vivência dentro da comunidade.

As pessoas que tem interesse em ingressar na instituição vão até lá com um responsável e conversa, demonstra seu interesse em internar-se (CT1).

Aqui, as internas vão por vontade própria, por vontade de se tratarem, por vontade de viver (CT13).

Outro dado importante é a inexistência da internação compulsória, priorizando os casos em que os indivíduos buscam auxílio por realmente o desejarem.

Aqueles que acham que não precisam, ele para na hora que quer, mas não para: "Ah... hoje eu paro", mas nunca para e só vai acabando com os bens da família. Aíonde eles (família) ligam para a compulsória. Aqui a gente não trabalha assim, trabalha com aquilo que o dependente quer (CT7).

Outros pontos importantes para todo o processo de tratamento que o dependente químico vai passar dentro da comunidade também são abordados durante as triagens, como por exemplo o nível de participação familiar, a disponibilidade dos familiares em participarem de atividades coletivas, o apoio dado pelos mesmos, visto que, durante a recuperação do dependente químico, a presença familiar deve atuar como um determinante.

No primeiro dia da triagem a família é recebida porpsicólogos ondesefazem perguntas sobretempo de uso de drogas(CT14).

A gente procura saber na triagem se a família está disposta a estar com a pessoa, que nós temos um trabalho aqui de conscientização da família, no caso das sequelas, das magoas, de restituição com a família, de perdão, pois tem que haver um perdão familiar de ambas as partes (CT27).

Embora muito próximas na concepção, cada comunidade possui uma metodologia de tratamento que éutilizada na recuperação dos dependentes químicos. Algumas possuem um cunho mais religioso enquanto outras abordam mais aspectos laborais, desse modo, cada entidade possui um regimento interno específico a ser seguido. Durante a triagem algumas comunidades optam por esclarecer as normas a serem seguidas e avaliar quais indivíduos estão dispostos a cumprir com as mesmas.

As vezes vem com a família, vem com pessoas direcionadas de igrejas, vem por amigos pessoas que são voluntárias que queremajudar, eaísão feitas as entrevistas normais explicando pra ele o funcionamento dentro da instituição (CT9).

O candidato tem que estar disposto a participar de todas as atividades. Não é permitido fumar no recinto e se o candidato concordar poderá ser aceito, mas tem que ser por vontade própria (CT17).

Na triagem a gente mostra o regulamento, mostra a comunidade (CT34).

Em uma das comunidades tem-se uma pré internação com o intuito de suspender o uso de qualquer droga antes do ingresso na instituição.

Acompanhamento com psicólogo. E lá ele fica alguns dias numa pré-internação. Já isento da droga, álcool e outras coisas ilícitas. Eapós essa internação são feitos os exames (CT26).

Não é incomum que dependentes químicos se encontrem envolvidos com traficantes assim como com policiais, de modo que, dentre os quesitos abordados durante a avaliação de triagem procura-se compreender se os mesmos realmente desejam receber o tratamento ou somente buscam um meio de fuga e esconderijo.

Euapresento primeiro oqueéa nossa realidade, praqueapessoapossarealmenteverochoquee veroquerrealmentedela, $e$ o que eu tenho pra oferecer, comoéquefunciona e tudo, enisso eu vou observando, vou buscando um pouco da história dele também. Alijána primeira entrevista, porqueéimportanteque a gente veja senão tá fugindo da polícia, senão tá correndo de traficante, se num quer só esconder (CT11).

Em outras situações os dependentes envolvem-se em diversas situações ilegais que culminam em processos judiciais, sendo este mais um ponto de interesse na investigação das comunidades no momento da triagem.

Analisamos a situação judicial de cada residente, identificação motivacional da residente (CT16).

Apóssentirqueo internotem interesse, preguntamos sobresua vida, a quanto tempo do uso de drogas, processo criminal, no que ele se envolveu durante esse período (CT18).

Há momentos nos quais o egresso já buscou auxílio em outras ocasiões, contudo, por motivos variados, não concluiu 
seu tratamento ou o concluiu e teve recaídas após retornar ao convívio social. Os responsáveis pela triagem, em alguns casos, avaliam tais situações, buscando compreender o comportamento do residente enquanto permaneceu internado, as possíveis causas de uma recaída, dentre outros fatores que possam colaborar com o sucesso do novo tratamento.

Normalmente as perguntas que eu pergunto é se ele quer mesmo ser libertado, eu tento ver se é ele mesmo que quer ou éa família que tá fazendo pressão, se tá vindo delemesmo, depois eu vou procurar quantas instituições ele já passou (CT30).

A análise do processo de triagem realizado pelas comunidades terapêuticas pesquisadas revelou que inúmeras esferas da vida do dependente químico são abordadas e avaliadas anteriormente à internação. Dentre os mais mencionados tem-se a vontade própria do indivíduo, a participação ativa da família durante o tratamento, o não envolvimento em problemas com traficantes ou policiais e a adequação às normas próprias da instituição que está tentando a internação.

\section{A adaptação dentro das comunidades terapêuticas}

Após os procedimentos de triagem, o agora residente, passa por uma importante etapa a ser vivenciada dentro da comunidade terapêutica, a adaptação àquela nova realidade para os próximos meses. O referido processo é retratado pelos entrevistados com sendo a base para a permanência do dependente químico, bem como para o sucesso do tratamento.

Durante as entrevistas foi possível observar que, apesar de haver algumas pequenas variações nos métodos adotados no processo de adaptação, todas as entidades pesquisadas reconhecem a necessidade de abordar o período de maneira adequada e acolhedora. Um número expressivo das comunidades pesquisadas compreende o momento de adaptação como sendo de transição, respeitando as necessidades iniciais dos indivíduos de permanecerem sozinhos integrando-se aos poucos à nova realidade.

A pessoa chega a gente acolhe. As vezes pegamos moradores de rua, então chegam drogados, então damos este tempo para a pessoa dormir, descansar, não mechemos com elas antes disso (CT2).

Primeiro dia eles geralmentechegam virado, normalmenteeles passam dormindo, já tem uns que chegam debilitado passam uma semana em recuperação, aígeralmente um pacientemais velho de casa e que fica por conta de cuidar e dar banho leva comida, cuida dele (CT12).
O primeiro momento na adaptação dos novos residentes, estes ficam livres das obrigações diárias exigidos dentro das comunidades. Há certa liberdade para recuperarem-se física e psicologicamente antes de iniciarem as respectivas atividades diárias. Os dias iniciais destinados à adaptação variam entre as entidades pesquisadas, mas, em geral, situam-se em três dias, sendo que posteriormente os indivíduos são apresentados à rotina da unidade, às regras e inseridos nas atividades laborais.

Os três primeiros dias nós deixamos ele a vontade para ele conhecer, fazer amizade. Depois desses três dias a gente começa a colocaronde ele vaipoder encaixarparapode ajudarele(CT7).

Quando ele chega ele tem três dias pra descansar, porque eles chegam muito debilitados, depois desses três dias é a hora que eles começam a fazer terapia da casa, começa a envolver (CT21).

Durante os três primeiros dias ele fica meio que observando e colocando suas necessidades pra depois ser colocado nas escalas, nos programas de estudo (CT33).

Outro ponto fundamental a ser abordado é a necessidade de conhecer o funcionamento da comunidade durante o processo de adaptação. Assim sendo, em algumas situações é indicado um residente mais antigo que ficará responsável por orientare esclarecer as dúvidas dos novos moradores.

Sempre tem um veterano que auxilia na adaptação, quanto às regras, nessa fase temos uma complacência especial, o veterano ajuda nas atividades até duas semanas, que é o tempo suficiente para integralização ao grupo (CT15).

É indicado um residente de nível avançado sero "anjo" acompanhará e estará a tirar algumas dúvidas por três semanas (CT24).

Nesse período inicial de adaptação, assim como conhecer o funcionamento da comunidade, o novo residente é apresentado aos demais moradores e funcionários bem como estimulado a relatar suas experiências, visto que, desse modo, estabelece-se o primeiro contato e insere o indivíduo naquela nova realidade.

É mostrado o local que cada residente se acomodará, uma apresentação em uma reunião com todos, apresentação dos funcionários da comunidade, quem são da casa. Também, cada residente recém-chegado conta sua história de vida (CT24). 
A avaliação do processo de adaptação vivenciado pelos dependentes químicos ao ingressarem nas comunidades demonstrou que, apesar de haver algumas individualidades em cada entidade o início, de um modo geral, é marcado pela valorização do espaço pessoal do novo residente. Tem-se uma ideia inicial de deixá-lo livre para recuperar-se física e psicologicamente para posteriormente enquadrar-se nas atividades diárias locais, favorecendo o sucesso terapêutico.

\section{A rotina diária dentro das comunidades terapêuticas}

Finalizado o período estipulado para a adaptação, os residentes começam a vivenciar de maneira mais intensa a rotina diária da comunidade, bem como suas respectivas normas. Cada atividade desempenhada e seus horários, assim como os limites impostos, participam do projeto final de recuperação e reinserção do dependente químico na sociedade.

$\mathrm{Na}$ rotina diária dentro das comunidades, algumas permitem o uso de cigarros, no caso de residentes que já eram dependentes, em horários específicos e quantidade diária estabelecida. Contudo, pode-se observar a existência de regras rígidas acerca do uso de cigarros e de dinheiro, sendo que muitas não permitem o tabagismo entre os residentes. Nas comunidades que não permitem, tanto cigarro quanto dinheiro ficam sob guarda e responsabilidade de um dos administradores ou encarregado da comunidade, usando-os de acordo com as necessidades.

Dinheiro não se pode ficar, cigarro eu libero porque a maioria fuma, limite cinco por dia (CT3).

Cigarro nós não permitimos aqui, dinheiro é todo repassado para a administração(CT1).

Ficamos com o dinheiro com um envelope com os nomes, o fim de semana saímos com eles para tomar sorvete, cortar um cabelo. Parajá serem socializados, comprar e pagar (CT2).

Aqui permitimos cigarro em três horários específicos, sempre após as refeições, onde eles podem utilizar seis cigarros por dia (CT31).

Durante a análise das entrevistas observou-se que as comunidades possuem uma rotina diária rígida, moldada conforme as respectivas necessidades. Existem horários para levantar, para as refeições, para as atividades laborativas, para as atividades de lazer, assim como para o descanso, que devem ser rigorosamente cumpridas. Tal fato elucida o estabelecimento de novos limites na vida dos dependentes químicos como parte do tratamento.

\begin{abstract}
Acorda 7:00 tem oração até 8:00. Aías 8:00 éo lanche (café da manhã), depois tem a terapia ocupacional arrumar as camas, organizar e logo em seguida vem o almoço que eles mesmos que fazem 12:00. Tem o horário do descanso e depois as 15:00 tem o lanche. As 17:00 tem o banho, as 18 h30 é a janta, por volta das 21:00 um lanche para dormir ou período para ver televisão, 22:00 hora de recolher (CT4).
\end{abstract}

Já uma outra comunidade relatou sua rotina diário da seguinte forma:

Acorda as 6:00, as 6:30 o café é servido, tem a oração antes do café como nas outras comunidades, logo depois vem pra capela e ficamos por lá até as 9:00, troca roupa, cada um vai para sua atividade conforme escala do monitor. As 11:30 éo almoço e as 13:30 eles retornam para suas atividades, ou tem reunião de grupo, depende do dia, na sexta tem psicólogo. $O$ banho é das 16:00 as 18:00, as vezes tem futebol, no decorrer temo cuidado com as roupas. As 18:00 tem a oraçãoe as 19:00 o jantar. As vezes tem uma viola, faz oração, normalmente encerra as 22:00. Depende do dia temo trabalho de prevenção de recaídas (CT15).

Na rotina diária das comunidades terapêuticas apresentam-se com uma forte base religiosa, inserindo em suas rotinas, além da laborterapia, momentos direcionados à recuperação espiritual do residente, ou seja, horários para missas, cultos, ensinamentos religiosos, dentre outras atividades.

Às 7:00 da manhã nós temos um devocional até as 8:00. Às 18:00 tem outro devocional e fecha a noite com um culto. Todos os dias menos na quarta, na quinta e no sábado que é filme educativo. Tem um grupo de pagode evangélico (CT7).

As 7:00 vão para a oração e junto uma leitura ou uma mensagembíblica comalguns ensinamentos. As 11:00 reúne-separa fazeruma oração efazumaleitura bíblica atéas 11:40. As 18:30 é o jantar e aí tem um tempo até as 19:30 que aí faz um culto e aíaté as 20:00 ou 21:00 (CT9).

Algumas outras atividades também estão presentes em suas rotinas, como consultas com psicólogos, momentos de lazer fora da comunidade, realização de atividade física, dias da semana específicos para receber visitas.

No domingo é livre, limpam a comunidade e recebem as visitas, e como eles são muitos as visitas revezam de 15 em 15 dias (CT12). 
Uma vez por semana tem atendimento com a psicóloga e acompanhamento com a líder de fase (CT16).

Há de ressaltar-se também que nas comunidades femininas que permitem a permanência de crianças pequenas com suas mães existem momentos específicos inseridos na rotina voltados para as mesmas.

\begin{abstract}
Depois dessas atividades tem o banho das crianças as 11:00, e a alimentação das crianças, depois tem o almoço delas que é as 12:00, onde fazemos a refeição. Depois do lanche fica livre para elas fazerem a alimentação das crianças e também a higienização delas. Hábrincadeiras com as mães e as crianças. As 19:00 é o jantar. E aí a noite fica livre, aí a gente vai fazer as vezes um momento de partilha, dividida entre os dias, tem atividades também a noite pra elas no período de uma horae as 21:00 todas estão descansando (CT1).
\end{abstract}

A observação à cerca da rotina empregada pelas $C T$ s, assim como algumas normas internas, possibilitou compreender que, apesar da existência de algumas variações, todas possuem horários diários rígidos e definidos para cada atividade, inserindo um novo conceito na vida do residente, assim como a base terapêutica sustentada pelas atividades laborativas que são desenvolvidas conforme a necessidade interna. As CTs que possuem uma base religiosa, adotam também em suas rotinas, momentos dedicados a cultos, orações e estudos religiosos. Além das atividades obrigatórias, há momentos destinados às atividades de lazer, bem como, dias e horários reservados para visitas. Todo o processo de triagem e adaptação inicial traz consigo dificuldades, que, após superadas, culminam no convívio do dependente com outros residentes, trocas de experiências, estabelecimento de novas relações e realização do tratamento conforme normas e rotinas definidas.

\section{Discussão}

As comunidades terapêuticas são instituições que têm por função a oferta de um ambiente protegido, técnica e eticamente orientado, que forneça suporte e tratamento aos usuários abusivos e/ou dependentes de substâncias psicoativas, durante período estabelecido de acordo com programa terapêutico adaptado às necessidades de cada caso ${ }^{11}$. É um lugar cujo principal instrumento terapêutico é a convivência entre os pares. Oferece uma rede de ajuda no processo de recuperação das pessoas, procurando resgar a cidadania por meio de novas possibilidades de reabilitação física e psicológica e de reinserção social"1.

Atuam por meio de tratamento residencial, ou seja, seu funcionamento é fundamentado na premissa de que, quando não seé possível promover mudanças no indivíduo dependente, passa a ser necessário alterar a sua condição, seu meio ambiente e removê-lo da situação onde o consumo ocorre. O processo terapêutico focaliza intervenções pessoais e sociais, atribuindo funções, direitos e responsabilidades ao indivíduo dependente em ambiente seguro em relação ao consumo de drogas ${ }^{12}$.

Os resultados demonstraram que o processo de triagem realizado anteriormente à admissão de novos residentes, apesar de particularidades que os diferem em determinados pontos, abrangem em comum, a necessidade do indivíduo de desejar realizar sua internação, sem pressão da família, mas sim por real desejo de mudança. Este princípio básico das reais comunidades terapêuticas fundamenta-se na premissa de que internações compulsórias, como as realizadas anteriormente à reforma psiquiátrica, foram substituídas por internações voluntárias, culminando em maior sucesso na conclusão do tratamento ${ }^{11,13,14}$. Outro fato que corrobora com tal realidade no processo de admissão é a ausência de um número suficiente de profissionais especializados, de modo que, o interesse do indivíduo no processo de mudança sobrepõe-se a todos os demais pontos ${ }^{13}$.

Outro ponto importante para o processo de triagem, bem como para o sucesso da terapêutica, revelado pelos resultados analisados, refere-se ao nível de participação familiar, a disponibilidade dos familiares em participarem de atividades coletivas, o apoio dado pelos mesmos, visto que, o uso compulsivo de substâncias ilícitas pode desestabilizar e romper laços de convivência e vínculos afetivos ${ }^{15,16}$. De tal modo, durante a recuperação do dependente químico, a presença familiar deve atuar como um determinante, já que, estes também são afetados, nas mais variadas ordens, pelas consequências do vício ${ }^{13,16-18}$. Assim sendo, a família não deve ficar à margem dos conflitos relacionados às drogas e, deve receber atenção especial no que tange a elaboração de programas sociais que atendam os contornos e suas especificidades, assim como, programas que reaproximem o dependente de seus familiares ${ }^{15,19}$.

Os resultados analisados demonstraram, em alguns casos, dependentes químicos que recorrem a este método de tratamento na tentativa de esquivar-se de perseguições policiais ou de traficantes, visto que sentem-se protegidos no ambiente da comunidade terapêutica, assim como escondidos e isolados. Entretanto, tal realidade interfere negativamente no sucesso da terapêutica adotada, já que o residente encontra-se ali não por interesse real em mudança, mas sim, momentaneamente, até poder retornar ao convívio com toda a sociedade. Em situações específicas como as acima mencionadas, os responsáveis pelos processos de triagem acabam por recusar tais dependentes químicos, respaldados pela premissa de insucesso terapêutico ${ }^{2,20}$. 
Após adentrar à comunidade, o agora residente passa por um processo de adaptação àquela nova realidade a ser vivida pelos próximos meses. Observou-se que inicialmente tem o seu espaço pessoal respeitado, por alguns dias, para que possa recuperar-se física e psicologicamente, e posteriormente enquadrar-se nas atividades desempenhadas pelos residentes. Tal processo inicial de adaptação apoia-se no pressuposto de que a dependência química, vista como doença, altera a vida do indivíduo em inúmeros aspectos, deixando-o absorto do mundo ao seu redor, dos limites sociais e da vida em comunidade.

Além desse período inicial de adaptação consigo mesmo, o novo residente é apresentado aos demais residentes e aos funcionários, bem como, inserido paulatinamente em atividades coletivas nas quais compartilham experiências, pontos chaves para o estabelecimento de relações de confianças. Essa apresentação inicial é frequentemente relacionada com melhor integração dos residentes, maior abertura para falar de problemas sensíveis, maior tolerância à dor e à frustração, seguimento das orientações dadas, cumprimento das exigências de funcionamento, continuidade no tratamento e mudança de comportamentos ${ }^{11,14,21}$.

O tratamento em uma comunidade terapêutica consiste em um modelo estruturado com limites, regras, horários e responsabilidades claras de relacionamentos interpessoais, estabelecidos em um ambiente isolado do contexto social e familiar, ordenado por regras que visam a favorecer relações francas e abertas entre os indivíduos. O tratamento em comunidade terapêutica segue alguns pressupostos básicos, com vistas a originar reflexão nas pessoas sobre suas capacidades de entender, querer, decidir e superar o uso de substâncias psicoativas ${ }^{2}$. O comportamento e o grau de interação social de cada interno são monitorados por internos e equipe, a fim de que todos possam se avaliar constantemente e se responsabilizar por seu próprio tratamento, fazendo escolhas, tomando decisões e desenvolvendo com auxílio dos profissionais, seu próprio projeto de vida ${ }^{2,14,22}$.

A interpretação dos resultados demonstrou que na maioria das comunidades analisadas, o processo terapêutico de recuperação e posterior reinserçãona sociedade, baseia-se na atividade laborativa, ou seja, os residentes são subdivididos conforme a necessidade da comunidade, eestimulados a trabalhar localmente, tais atividades visam possibilitar a convivência em grupo, preencher os dias dos mesmos, bem como, prepara-los para a reinserção social. Observase, desse modo, que o processo terapêutico preconiza intervenções individuais e sociais com atribuição de funções, direitos e responsabilidades ao indivíduo dependente químico².

Além das atividades laborativas desenvolvidas, outro ponto fundamental, observado pelos resultados, presentes nas comunidades, refere-se à pratica religiosa, de modo que, compondo a rígida rotina das comunidades terapêuticas, temse momentos específicos destinados à cultos religiosos, ensino da palavra, grupos de orações, dentre outros. As comunidades não atuam como uma religião. O que se observa, é a existência de fundadoras e/ou mantenedoras religiosas, confessionais, que viabilizam a existência destas entidades. Assim, estuda-se e divulga-se a Bíblia, disponibiliza-se palestras de cunho religioso e motivacionais, dedica-se momentos diários à realização de cultos e/ou missas, assim como, desenvolvem atividades de lazer vinculadas à religião ${ }^{22-24}$.

\section{Conclusão}

Os processos de triagem realizados pelas comunidades terapêuticas pesquisadas apesar de apresentar determinados pontos de divergências, configuram-se, de modo geral, como uma abordagem abrangente do indivíduo, baseada em ressaltar temas de cunho pessoal, em especial, o real interesse do dependente químico em ingressar no processo de tratamento, visto que, trata-se de um período sobrecarregado de mudanças, abstinência das drogas e novos aprendizados. Além disso, a participação familiar apresenta-se nos discursos como sendo de suma importância durante o processo de triagem, assim como, durante todo o tratamento, pois ações coletivas são planejadas objetivando reestabelecer os laços fragilizados pelo consumo das drogas, culminando em um maior sucesso terapêutico e menores índices de recaída.

Posteriormente aos procedimentos de triagem, o residente passa por uma nova etapa, a adaptação àquela nova realidade, sendo que tal momento é referido como base para a permanência do dependente químico bem como para o sucesso terapêutico. Apesar de algumas pequenas variações entre os métodos adotados nos processos de triagem, todas as entidades reconhecem a necessidade de uma abordagem adequada, entendendo este momento como sendo de adaptação respeitando a individualidade de cada residente.

A rotina das entidades baseia-se na necessidade individual de cada uma, sendo que as normas pré-estabelecidas devem ser rigorosamente cumpridas. Tem-se horários fixos definidos para todas as atividades, de modo que os residentes passam a vivenciar uma realidade até então desconhecida, pautada na disciplina e organização. Algumas comunidades apresentam, além da laborterapia, uma base mais religiosa, com inserção em suas rotinas de momentos destinados à recuperação espiritual do dependente químico, momentos de oração, missas e cultos.

A análise das entrevistas possibilitou compreender os três processos iniciais do funcionamento de comunidades terapêuticas. O entendimento desse fenômeno, especificamente rela- 
cionado às comunidades terapêuticas pode auxiliar na melhor qualificação desses processos de recebimento do indivíduo, desde o momento em que ele chega à comunidade terapêutica, bem como saber os impactos de mudanças que ocorreram devido à mudança de contexto social.

\section{Referências}

1. Silva GG, Pinto MR, Machineski GG. Percepção dos familiares de usuários de substâncias psicoativas em relação ao tratamento em comunidade terapêutica. Cogitare Enfermagem. 2013;18(3):475-81.

2. Gomes RM. Comunidade terapêutica e (re) educação. Revista Segurança Urbana e Juventude. 2010;3(2):1-18.

3. Brasil. A Política do Ministério da Saúde para atenção integral a usuários de álcool e outras drogas. Brasília: Ministério da Saúde, 2003. Disponível em: <http://bv sms.saude.gov.br/bvs/ publicacoes/pns_alcool_drogas.pdf>. Acesso em: 28 mar. 2017. 4. De Leon G. A comunidade terapêutica: teoria, modelo e método. São Paulo: Loyola; 2003.

5. Raupp LM, Milnitsky-Sapiro C. A "reeducação"de adolescentes em uma comunidade terapêutica: o tratamento da drogadição em uma instituição religiosa. Psicologia: Teoria e Pesquisa. 2008;24(3):361-8.

6. Lavara N. La eficácia de las comunidades terapêuticas a examen. 2004. Disponível: <http:www.entorno social.es/documentn04/aass5502.html>. Acesso em: 15 out. 2018.

7. Brasil. Portaria n. 3088, de 23 de dezembro de 2011. Institui a rede de atenção psicossocial para pessoas com sofrimento ou transtorno mental e com necessidades decorrentes do uso de crack, álcool e outras drogas, no âmbito do Sistema Único de Saúde (SUS). Disponível em: <http://www.brasilsus.com.br/ legislacoes/gm/11127630 88.html>. Acesso em: 28 mar. 2017. 8. Brasil. RDC ANVISA n ${ }^{\circ} 29$, de 30 de junho de 2011. Dispõe sobre os requisitos de segurança sanitária para o funcionamento de instituições que prestem serviços de atenção a pessoas com transtornos decorrentes do uso, abuso ou dependência de substâncias psicoativas. Disponível em: $<$ http://bvsms.saude. gov.br/bvs/saudelegis/ navisa/2011/res00 29_30_06_2011. html>. Acesso em: 09 mar. 2017.

9. Dantas CC, Leite JL, Lima SBS, Stipp MAC. Teoria fundamentada nos dados - aspectos conceituais e operacionais: metodologia possível de ser aplicada na pesquisa em enfermagem. Rev Latino-Am Enfermag. 2009;17(4):573-9.

10. Garque KCGD. Teoria Fundamentada: nova perspectiva à pesquisa exploratória. In: Mueller SPM. (Org.) Métodos para a pesquisa em ciências da informação. Brasília: Thesaurus; 2007. 11. Perrone PAK. A comunidade terapêutica para recuperação da dependência do álcool e outras drogas no Brasil: mão ou contramão da reforma psiquiátrica? Ciência e Saúde Coletiva. 2014;19(2):569-80.

12. Sabino NM, Cazevane SOS. Comunidades terapêuticas como forma de tratamento para dependência de substâncias psicoativas. Revista Estudos de Psicologia. 2005;22(2):167-74.

13. Rezende MM, Jesus CF. Dirigentes de instituições que assistem dependentes químicos no Vale do Paraíba. Estudos de Psicologia. 2008;25(4):499-507.

14. Scaduto AA, Santos MA. Adesão aos princípios da Comunidade Terapêutica e processo de mudança ao longo do tratamento. Psicologia: Ciência e Profissão. 2015;35(3):781-96. 15. Ruiz VRR, Marques H. A internação compulsória e suas variáveis: reflexões éticas e socioculturais no tratamento e reinserção do paciente na sociedade. Revista Psicologia e Saúde. 2015;7(1):1-8.

16. Pinho PH. Os desafios na atenção aos usuários de álcool e outras drogas e a reabilitação psicossocial. 2009. 225 f. Dissertação Escola da Universidade de Enfermagem de São Paulo, São Paulo, 2009.

17. Fonseca EM, Bastos Fl. Políticas de redução de danos em perspectiva: comparando as experiências americana, britânica e brasileira. In: Acserald G. (Org.) Avessos do prazer: drogas, AIDS e direitos humanos. 2. ed. Rio de Janeiro: Fiocruz; 2005.

18. Schneider J. Trama terapêutica: um estudo sobre a (re) constituição da identidade de usuários de drogas. Caderno de campo. 2010;19:1-384.

19. Pacheco AL, Scisleski A. Vivências em uma comunidade terapêutica. Revista Psicologia e Saúde. 2013;5(2):165-73.

20. Carbonera A, Silva AF, Prado JAFA. A luta de uma mulher contra a dependência química: um olhar da Gestalt-terapia. Revista IGT na Rede. 2014;11(21):297-307.

21. Machado LA, Veloso A. O desenvolvimento da confiança nas comunidades terapêuticas e o seu impacto na adesão ao tratamento. Psicologia: Reflexão e Crítica. 2011;24(3):523-32.

22. Minayo MCS, Ribeiro FML. As Comunidades Terapêuticas religiosas na recuperação de dependentes de drogas: o caso de Manguinhos, RJ, Brasil. Interface - Comunicação, Saúde, Educação. 2015;19(54):515-26.

23. Luiz MC, Gomes RM. Educação não formal e comunidade terapêutica para dependentes químicos: articulação de processos educativos em práticas sócias. Revista Holos. 2015;31(3):393-403. 24. Gehring MR. Comunidade Terapêutica: análise sócio demográfica, perspectivas, percepções e motivos para recaída de residentes do esquadrão da vida de Bauru - SP. Revista do Laboratório de Estudos da Violência da UNESP. 2014;14:71-97, 2014. 